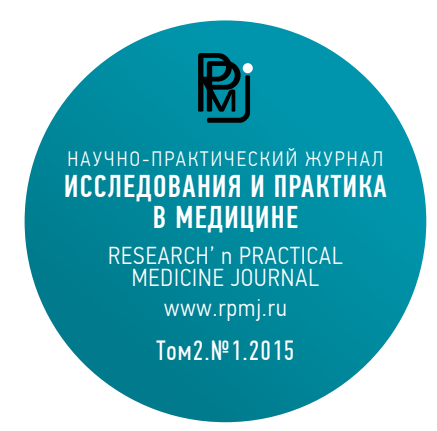

Ключевые слова: рак, шейка матки, заболеваемость, смертность, скрининг, злокачественные новообразования шейки матки

Keywords:

cancer, cervix, morbidity, mortality, screening, malignant neoplasms of cervix

DOI:10.17709/2409-2231-2015-2-1-36-41

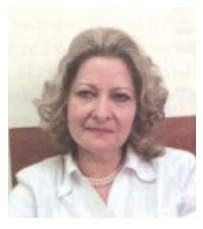

Для корреспонденции:

Трушина Ольга Ивановна д.м.н., ФГБУ мНИОИ им. П.А. Герцена филиал ФГБУ «ФМИЦ им. П.А. Герцена Минздрава России, с.н.с. гинекологического отделения отдела опухолей репродуктивных и мочевыводящих органов Адрес:125284 г. Москва,

2-й Боткинский проезд д.3 Телефон: +7 (495) 945-88-19 E-mail: 0.trushina@list.ru Статья поступила 12.02.2015 принята к печати 05.03.2015

For correspondence:

Trushina Olga Ivanovna -

MD, Herzen Federal Medical Research Center of the Ministry of Health of the Russian Federation, senior researcher of the gynecological Department of the division of tumors of the reproductive and urinary organs.

Address; 3, 2 Botkinskiy proezd, Moscow,

Russian Federation, 125284

E-mail: o.trushina@list.ru

\section{СКРИНИНГ РАКА ШЕЙКИ МАТКИ - НЕРЕШЕННЫЕ ПРОБЛЕМЫ}

\author{
Каприн 'А.Д., Новикова²Е.Г., Трушина
}

1 ФГБУ «НМИРЦ» Минздрава России (Обнинск, Российская Федерация)

249036, Российская Федерация, Калужская область, г. Обнинск, ул. Королёва, д. 4

${ }^{2}$ МНИОИ им. П.А. Герцена - филиал ФГБУ «НМИРЦ» Минздрава России (Москва, Российская Федерация)

125284, Российская Федерация, Москва, 2-ой Боткинский проезд, дом 3

\section{Резюме}

Проблема рака шейки матки (РШМ) в течение многих десятилетий продолжает оставаться в центре внимания ведущих зарубежных и отечественных онкологов. Злокачественные опухоли шейки матки занимают лидирующую позицию среди злокачественных новообразований органов репродуктивной системы у женщин, уступая лишь раку молочной железы, несмотря на наличие гораздо более эффективного скрининга по сравнению с этим заболеванием. По прогностическим оценкам экспертов (с учетом роста населения и увеличения ожидаемой продолжительности предстоящей жизни) к 2020 г. в развивающихся странах рост показателей заболеваемости и распространенности РШМ составит $40 \%$, а в развитых странах $-11 \%$. Если сегодня не проводить своевременные мероприятия по профилактике и лечению РШМ, то после 2050 г. ежегодно в мире РШМ будет заболевать 1 млн. женщин. В течение последнего десятилетия в России отмечается постепенный рост заболеваемости РШМ: среднегодовой прирост составил $2,21 \%$, общий $-25,18 \%$. РШМ является одной из нозологических форм, удовлетворяющих всем требованиям популяционного скрининга. Существующие в настоящее время в России нормативные документы не дают однозначных ответов на вопросы, касающиеся возраста начала проведения скрининга РШМ и временного интервала между тестами, отсутствует четкая программа организованного цитологического скрининга РШМ.

\section{THE CERVICAL CANCER SCREENING - UNSOLVED PROBLEMS}

Kaprin' A.D., Novikova² E.G., Trushina² O.I., Gretzova² O.P.

${ }^{1}$ NMRRC (Obninsk, Russian Federation), 4, st. Korolev, Kaluga region, Obninsk, Russian Federation, 249036

${ }^{2}$ P. Hertsen Moscow Oncology Research Institute - branch of the National Medical Research Radiological Centre of the Ministry of Health of the Russian Federation (Moscow, Russian Federation)

3, 2 Botkinskiy proezd, Moscow , Russian Federation,125284

\section{Summary}

The problem of cervical cancer (CC) for many decades continues to be the center of attention leading foreign and domestic oncologists. Malignant cervical tumors occupy the leading position among malignant neoplasms of reproductive system in women, second only to breast cancer, despite having far more effective screening compared with this disease. On predictive expert estimates (taking into account population growth and the expected increase in life expectancy) by 2020 in developing countries, the rising incidence and prevalence of cervical cancer is $40 \%$, while in developed countries - $11 \%$. If we do not perform timely interventions for prevention and treatment of cervical cancer, after 2050 cervical cancer every year in the world will become sick 1 million women. In the last decade in Russia there has been a gradual increase in the incidence of cervical cancer: average annual growth rate of $2.21 \%$, General $25,18 \%$. Cervical cancer is one of nosological forms that meet all the requirements of population-based screening. The current Russian normative documents do not give clear answers to questions concerning the age of onset of cervical cancer screening and the time interval between tests, no clear program organized cytological screening of cervical cancer. 
Проблема рака шейки матки (РШМ) в течение многих десятилетий продолжает оставаться в центре внимания ведущих зарубежных и отечественных онкологов. По данным многочисленных мировых статистических исследований злокачественные опухоли шейки матки занимают лидирующую позицию среди злокачественных новообразований органов репродуктивной системы у женщин, уступая лишь раку молочной железы. В структуре онкогинекологической патологии РШМ составляет $15 \%$, а смертность от этого заболевания достигает $8 \%$. В результате цервикального скрининга абсолютное снижение смертности от РШМ составляет до 70\% (Старинский и др., 2008). Более того, с учетом длительного развития опухоли (8-10 лет) проведение скрининга позволяет снизить не только смертность, но и заболеваемость РШМ за счет лечения патологии на стадии предопухолевых изменений (Новик, 2010). Ежегодно в мире диагностируется около 500 тыс. новых случаев РШМ, а 274 тыс. умирают от этого заболевания (Комплексная..., 2010).

Наиболее высокие показатели заболеваемости РШМ зафиксированы в странах Южной и Центральной Америки, Африки, Южной и Центральной Азии, на долю которых приходится $78 \%$ случаев. В то же время массовые скрининговые программы на государственном уровне в странах Северной Америки и Западной Европы за последнее десятилетие привели к значительному снижению показателей заболеваемости и смертности от РШМ (его доля составляет 4,4\% от числа всех злокачественных новообразований у женщин) (Аксель, 2010). По прогностическим оценкам экспертов (с учетом роста населения и увеличения ожидаемой продолжительности предстоящей жизни) к 2020 г. ожидается рост показателей заболеваемости РШМ до 40\% в развивающихся странах, тогда как в развитых странах только до $11 \%$. Если сегодня не проводить своевременные мероприятия по профилактике и лечению РШМ, то после 2050 г. ежегодно в мире РШМ будет заболевать 1 млн. женщин (Стерн, Китченер, 2011). Таким образом, оставаясь наиболее частой онкогинекологической патологией, РШМ является серьезной проблемой здравоохранения во всем мире.

В России заболеваемость злокачественными опухолями шейки матки не имеет тенденции к снижению. В общей структуре онкологической заболеваемости РШМ составляет 5,3\%, занимая 6-е место, а среди органов репродуктивной системы - третье (14\%) после рака молочной железы (54,5\%) и эндометрия (19,3\%). В 2013 г. зарегистрировано 15427 впервые заболевших РШМ и погибло более 6522 пациенток. В течение последнего десятилетия отмечается постепенный рост заболеваемости РШМ: среднегодовой прирост составил 2,21\%, общий $-25,18 \%$. (рис. 1).

По-прежнему остается высоким удельный вес запущенных стадий $(35,9 \%)$ и показатель одногодичной летальности (16,5\%) (Каприн и др., 2015). Такой статистический показатель как летальность больных в течение года с момента установления диагноза злокачественного новообразования достоверно свидетельствует о фактической запущенности опухолевого процесса, а также качестве лечения.
РШМ является одной из нозологических форм, удовлетворяющих всем требованиям популяционного скрининга: заболевание является проблемой здравоохранения; имеет длительный период развития от преинвазивной стадии до инвазивного рака (до 10 лет); надежно распознается в преклинической фазе; подвергается эффективным методам лечения; обладает высоко эффективным цитологическим скрининг-тестом (American..., 2009). Следовательно, жизнь многих заболевших женщин можно было бы сохранить.

Средний возраст женщин с впервые установленным диагнозом РШМ в 2013 г. составил 51,9 года, в 2003 г. аналогичный показатель составил 53,9 года. За последнее десятилетие отмечается заметное "омоложение» РШМ за счет увеличения числа заболевших женщин в репродуктивном возрасте: до 70\% (Каприн и др., 2015; Чиссов и др., 2010). Интенсивное повышение показателя заболеваемости РШМ особенно заметно в группе женщин моложе 29 лет, где за последние 20 лет прирост составил более 200\%. РШМ занимает первое место среди всех онкогинекологических заболеваний в возрастной группе женщин до 30 лет. У женщин 25-40 лет инвазивные формы РШМ составляют около $30 \%$. Одной из основных причин смертности в этом возрасте является цервикальный рак, занимая 2-е место после рака молочной железы (Shipitsyna, et al., 2011).

Несомненно, факт неуклонного роста цервикальной онкопатологии, неблагоприятная тенденция к омоложению болезни является тревожным и однозначно свидетельствует о необходимости разработки и внедрения эффективных профилактических мероприятий по предупреждению этого грозного онкогинекологического заболевания. И если сегодня не проводить активный скрининг РШМ по всей территории России, то заболеваемость РШМ никогда не уменьшится.

Частота РШМ неодинакова в различных регионах страны, что зависит, прежде всего, от различий в организации и эффективности профилактических программ, а также от изменений демографического компонента (общая численность и распределение по полу и возрасту). Высокий уровень заболеваемости на 100 тыс.

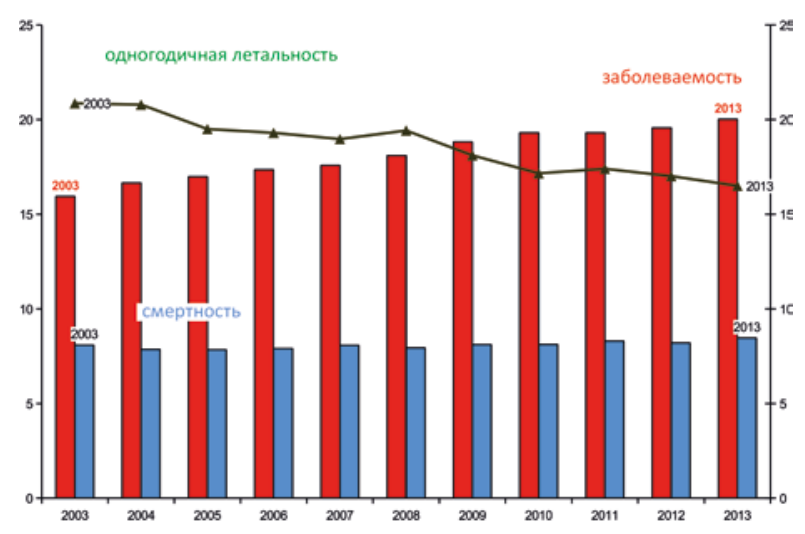

Рисунок 1. Динамика показателей заболеваемости (на 100 тыс. женского населения), смертности (на 100 тыс. женского населения) и одногодичной летальности (\%) от РШМ, 2003-2013 гг., Россия

Исследования и практика в медицине. 2015, т. 2, № 1, с.36-41 
женского населения в 2013 г. зарегистрирован в Магаданской области $(43,6)$, Республике Бурятия $(39,2)$, Камчатском крае $(38,8)$. В то же самое время в ряде регионов страны отмечено значительное снижение заболеваемости РШМ: например, в Чувашии - 12,2; Башкортостане 14,6; Москве - 13,0 (Каприн и др., 2011).

Любой случай инвазивного РШМ следует считать последствием упущенных возможностей диагностики предрака, так как заболевание имеет длительный период развития (10 и более лет) в течение которого оно должно быть диагностировано на этапе предопухолевых цервикальных изменений, а их лечение становится основным способом профилактики рака шейки матки (Arbyn, et al., 2009).

Теоретические обоснования цитологического скрининга РШМ были сформированы в 40-х годах прошлого столетия. К этому периоду стало ясно, что при распространенном РШМ (III-IV стадия) эффективное лечение возможно лишь у небольшого числа больных, тогда как методы ранней диагностики и профилактики цервикального рака могут способствовать существенному изменению ситуации. После классических работ Папаниколау и других авторов было доказано, что цитологический метод исследования является весьма чувствительным в диагностике цервикальных интраэпителиальных неоплазий (CIN), карциномы in situ, микроинвазивного и скрытого инвазивного рака (Урманчеева, 2006).

Сегодня используются три морфологические классификации цервикальных мазков: по Папаниколау (Паптест, Рар-smear, Рар-мазок), ВО3, Bethesda System (Профилактика..., 2012).

Согласно классификации по Папаниколау выделяют 5 классов гинекологических мазков: І класс - нормальные клетки; II класс - воспалительный тип мазка; III класс -дискариоз, морфологические изменения эпителиальных клеток; IV класс - атипические клетки, подозрительные в отношении злокачественности; V класс - злокачественные изменения клеток.

Классификация ВО3 (Cervical intraepithelial Neoplasia): IN I - легкая цервикальная дисплазия; CIN II - умеренная дисплазия; CIN III - тяжелая дисплазия и Cr in situ.

В связи с появлением новых знаний о роли ВПЧ в патогенезе РШМ и с целью более эффективной передачи информации от лаборатории врачам, повышения воспроизводимости результатов цитологической диагностики и обеспечения стандартизации лечения выявленных нарушений в 1988 г. в г. Бетесда была разработана Терминологическая система Бетесда (Terminology Bethesda System, TBS) (The Bethesda...,2004). K еe основным терминологическим характеристикам относятся: ASC (Atypical glandular cells) - атипичные гландулярные (железистые) клетки; ASC (Atypicals squamous cells) - атипичные сквамозные клетки плоского эпителия; ASC-US (Atypicals squamous cells undertermined significance) атипичные клетки плоского эпителия неясного значения; ASC-H (Atypicals squamous cells cannot exclude HSIL (high grade squamous intraepithelial lesion)) - атипичные клетки плоского эпителия, не позволяющие исключить поражение эпителия тяжелой степени; CIN I, II, III (Cervical intraepithelial neoplasia I, II, III) -цервикаль- ная интраэпителиальная неоплазия I, II и III степени); CIS (Carcinoma in situ) - рак in situ; HSIL (High grade squamous cells intraepithelial lesion) - высокая степень плоскоклеточного интраэпителиального поражения; LSIL- (Low grade squamous cells intraepithelial lesion) низкая степень плоскоклеточного интраэпителиального поражения; NILM (Negative for intraepithelial lesion or malignancy) - негативные в отношении интраэпителиального поражения или злокачественности; NOS (Not otherwise specified) - без дополнительного уточнения.

Чувствительность цитологического исследования по данным различных исследователей составляет от 66\% до 83\% (Шабалова, Касоян, 2010). В 70-90\% случаев причиной ложноотрицательных цитологических ответов является плохой забор материала для цитологического исследования и лишь в 10-30\% - ошибочная интерпретация цитологических данных. Считается, что до 30\% случаев РШМ развивается у женщин, которые регулярно проходили цитологический скрининг, но при этом забор материала или интерпретация результатов были ошибочны, то есть давали ложноотрицательные результаты, которые регистрируются даже в лучших скрининговых программах (European..., 2008). Все эти аргументы послужили основой для поиска новых скрининговых технологий, среди которых предлагаются автоматизированные системы жидкостного цитологического анализа, обеспечивающие достаточную точность результатов скрининга и высокую производительность.

Ожидаемыми результатами цитологического скрининга являются: выявление предопухолевых заболеваний, ранних стадий рака, в первую очередь рака in situ, и их своевременное лечение; изменение структуры заболеваемости РШМ за счет увеличения числа ранних стадий и уменьшения распространенных и запущенных форм; снижение смертности и одногодичной летальности, инвалидизации женского населения и заболеваемости РШМ путем выявления и последующего лечения предопухолевых заболеваний шейки матки (Sasieni, et al.,2009). Задачи скрининга могут быть достигнуты при преемственности в работе женских смотровых кабинетов, женских консультаций и онкологических учреждений, так как важно не только выявить патологию шейки матки, но и провести ее своевременное лечение.

Выделяют две системы цитологического скрининга рака шейки матки: организованный (систематический) скрининг и неорганизованный (спорадический) скрининг. В первом случае определяются группы женщин, подлежащих скринингу, которые активно приглашаются принять участие в обследовании. Во втором случае, обследуются лишь женщины, которые обратились в лечебно-профилактические учреждения по поводу каких-нибудь причин. Эффективность организованного скрининга выше, чем неорганизованного.

Скрининг РШМ предусматривает три этапа:

I этап (популяционный скрининг) - деление на подгруппы здоров/болен на основании визуальных осмотров;

II этап (диагностический скрининг) - деление на подгруппы по степени онкологического риска на основании данных дообследований: фоновые заболевания, предрак, рак; 
III этап - формирование групп диспансерного наблюдения для мониторинга и коррекции по нозологическому принципу.

В настоящее время диагностической доктриной раннего выявления РШМ является широкий охват цитологическим скринингом женского населения (75-90\%). Результатом, подтверждающим эффективность такого режима скрининга, является снижение показателей заболеваемости и смертности от РШМ, а также изменение структуры заболеваемости, стабилизация показателей смертности за счет увеличения количества ранних стадий рака, уменьшения запущенных форм (Anttila, et al., 2009). Следует отметить, что из-за длительного периода развития рака шейки матки частота проведения раундов цитологического скрининга имеет значительно меньшее влияние на его эффективность по сравнению с широтой охвата.

Информативность цитологического метода при интраэпителиальных дисплазиях и ранних формах РШМ варьирует от 50 до 87\%, поэтому важность обследования другими методами исследования очевидна. Подтверждение этиологической роли ВПЧ в развитии РШМ привело к тому, что тестирование на ВПЧ ввиду его гораздо более высокой чувствительности по сравнению с цитологическим исследованием для выявления CIN высокой степени (CIN II+) стало рассматриваться как важнейший элемент скрининга этого заболевания (Ужегова и др., 2007).

Международными экспертными организациями были сформулированы следующие рекомендации по применению ВПЧ-теста в скрининге РШМ: в первичном скрининге у женщин старше 30 лет в сочетании с цитологическим исследованием или в качестве самостоятельного теста; при ведении пациенток с неопределенными результатами цитологического исследования; для мониторинга терапии цервикальных поражений высокой степени (World Health..., 2006).

Немаловажным вопросом является периодичность, возраст начала и окончания цервикального скрининга. В идеале скринингу РШМ рекомендуют подвергать женщин в возрасте 25-65 лет ежегодно первые два года, а затем при отрицательных результатах - каждые три года (ВО3). Однако в последние годы все чаще стали появляться сообщения о высокой частоте выявления предраковых состояний и даже РШМ у женщин в возрастной группе до 25 лет, поэтому вопрос возраста женщин-участниц скрининга требует дальнейшего обсуждения.

В США, согласно новым рекомендациям, впервые женщин привлекают к обследованию в возрасте 21 года, но не ранее. Большинство стран Европы (Великобритания, Бельгия, Франция, Италия и др.) приняли прагматичное решение начинать скрининг с 25 лет. В некоторых странах Европы (Финляндия, Нидерланды, Эстония, Литва) на обследование женщин впервые приглашают в возрасте 30 лет (Sasieni, et al., 2003).

До сих пор открытым остается вопрос о периодичности проведения скрининга в связи с тем, что в разных странах приняты различные межскрининговые интервалы. По расчетам специалистов, эффективность скрининга РШМ при интервалах между обследованиями один раз в три года лишь незначительно уступает эффективности ежегодного скрининга - не более 2\%. Оптимальным межскрининговым интервалом считают 3-5 лет при охвате населения в пределах 75-80\% (Crusswell, et al., 2010).

В нашей стране цитологический метод исследования при массовых профилактических гинекологических осмотрах стали применять с 1964 г., а с 1977 г. на основании приказа Минздрава СССР № 1253 от 30.12.1976 г. была создана сеть централизованных цитологических лабораторий (ЦДЛ). Однако эта практика была утеряна и за последние более чем 20 лет мы наблюдаем прирост заболеваемости РШМ в России: с 12,4 на 100 тыс. женского населения в 1989 г. до 20,0 на 100 тыс. женского населения в 2013 г. Не отмечается и статистически достоверного снижения удельного веса больных с запущенными стадиями заболевания РШМ (таблица 1).

В настоящее время общегосударственных программ скрининга РШМ в России нет, хотя с 2013 г. начался новый этап диспансеризации населения страны, в которую включены мероприятия по выявлению патологии шейки матки (Русакевич, 2010).

Одним из основных критериев оценки диагностического компонента помощи онкологическим больным в учреждениях общей лечебной сети административной территории является показатель запущенности, который в 2013 г. составил 36,5\%, то есть более трети женщин выявляются с распространенным опухолевым процессом. Данный процент является недопустимо высоким при диагностике новообразований визуальных локализаций. Такие удручающие показатели объясняются тем, что в 1991 г. по ряду социальных и экономических причин разрушилась так называемая «советская» система диспансеризации, практически полностью прекратила существование созданная повсеместно сеть смотровых кабинетов, осуществлявших цитологический скрининг женского населения страны.

Таблица 1

Динамика показателей распространенности опухолевого процесса и активного выявления РШМ, 2008-2013 гг.,\%, Россия.

\begin{tabular}{|c|c|c|c|c|c|c|}
\hline & 2008 & 2009 & 2010 & 2011 & 2012 & 2013 \\
\hline І-ІІ стадия (до 2011 г. суммарно) & 58,5 & 59,7 & 59,8 & $28,9+33,1$ & $29,0+31,3$ & $30,4+30,8$ \\
\hline III стадия & 29,5 & 28,3 & 29,0 & 27,3 & 28,6 & 27,0 \\
\hline IV стадия & 10,1 & 9,6 & 9,1 & 8,6 & 9,1 & 9,5 \\
\hline Стадия не установлена & 1,9 & 2,4 & 2,1 & 2,1 & 2,0 & 2,3 \\
\hline Выявлено активно & 28,9 & 28,2 & 28,9 & 29,8 & 31,1 & 32,2 \\
\hline
\end{tabular}


Степень охвата населения России профилактическими осмотрами на сегодняшний день в России невысокая $(29,8 \%)$, что свидетельствует об отсутствии профилактических обследований всех категорий населения и неадекватности скрининговых мероприятий современным возможностям медицины. До сих пор нет четкой программы организованного цитологического скрининга РШМ. Приказами Министерства здравоохранения регламентированы лишь общие положения о целесообразности ежегодных профилактических осмотров женщин, начиная с 18 лет и старше, с цитологическим исследованием мазков с экто- и эндоцервикса. Фактически В России проводится “оппортунистический скрининг», в котором участвует не более 30\% женского населения, а межскрининговый интервал варьирует от 1 до 5 лет

\section{Список литературы:}

1. Аксель Е.М. Статистика злокачественных новообразований женской половой сферы.//Онкогинекология 2012. № 1. C. $18-23$.

2. Каприн А.Д., Старинский В.В., Петрова Г. В. Злокачественные новообразования в России в 2013 году (заболеваемость и смертность). М: ФГБУ «МНИОИ им. П. А. Герцена» Минздрава России 2015; 250 с.

3. Каприн А.Д., Старинский В. В., Петрова Г. В. Основные показатели состояния онкологической помощи населению Российской Федерации в 2013 г. М: ФГБУ «МНИОИ им. П. А. Герцена» Минздрава России. 2014. 235 с.

4. Коломиец Л.А., Чуруксаева О.Н., Уразова Л.Н., Чернышова А. Л., Молчанов С.В., Мунтян А.Б., Замкова О.В., Видяева И.Г. Вакцинация против ВПЧ - первичная профилактика рака шейки матки. Томск: Изд-во «Печатная мануфактура», 2011. 116 с.

5. Комплексная борьба с раком шейки матки: Краткое практическое руководство.ВОЗ, 2010. 290 с.

6. Новик В..И. Скрининг рака шейки матки.//Практическая онкология. 2010: № 2. С. 66-73.

7. Профилактика рака шейки матки: Руководство для врачей./Под. Ред. Г. Т. Сухих и В.Н. Прилепской. М.: МЕДпрессинформ. 2012. 192 с.

8. Русакевич П.С. Вирусные изменения шейки матки, ассоциированные с доброкачественными и предраковыми поражениями: новые возможности лечения и профилактики/Русакевич П.С., Шмак К.И., Гришанович Р. В.//Медицинские новости. 2010. № 3. С. 79-84.

9. Старинский В.В., Петрова Г.В., Грецова О.П. Эпидемиология злокачественных новообразований/В кн. «Руководство по онкологии»/Под ред. В.И. Чиссова, С.Л. Дарьяловой. М.: ООО «Медицинское информационное агентство». 2008. С. 30-44.

10. Стерн Л. Питер, Китченер С. Генри. (Ред.) Вакцины для профилактики рака шейки матки. Под редакцией Питера Л. Стерна, Генри С. Китченера. Москва, 2011. 192 с.

11. Ужегова Ж.А., Григорян О.Р., Григорян Е.Н. Современные возможности диагностики и лечения предраковых заболеваний шейки матки.//Российский вестник акушера-гинеколога. 2007. № 1. Р.28-34.

12. Урманчеева А.Ф.Рак шейки матки: скрининг, диагностика и стадирование. Образовательный курс Европейского общества по медицинской онкологии//Онкогинекология. 2006. P.275-289.
(Коломиец и др., 2011). В нашей стране усилия сконцентрированы почти исключительно на повышении эффективности лечения, однако очевидна настоятельная необходимость изменения стратегии в сторону интеграции региональных противораковых программ, разработанных на основе современных представлений о канцерогенезе, факторах риска, методах диагностики и лечения.

Таким образом, раннее выявление предопухолевой патологии и РШМ является актуальной проблемой современного общества. Снижение показателей заболеваемости и смертности от этого заболевания зависит от совершенствования и внедрения методов скрининга РШМ, что приведет к своевременному распознаванию и лечению ранних форм злокачественных цервикальных новообразований.

13. Чиссов В.И., Старинский В.В., Мамонтов А.С. Алгоритмы ведения онкологических заболеваний у населения Российской Федерации: Методические рекомендации. М: ФГБУ «МНИОИ им. П. А. Герцена» Минздрава России. 2010.

14. Шабалова И.П., К Касоян К.Т. Цитологическая диагностика заболеваний шейки и тела матки. Триада Тверь. 2010. 382 с.

15. American College of Obstetricians and Gynecologiests. ACOG Practice Bulletin number 109, December 2009: Cervical cytology screening.//Obstet Gynecol. 2009. V.114 P.1409-1420.

16. Anttila A, von Karsa L, Aasmaa A, et al. Cervical cancer screening policies and coverage in Europe.//Eur J Cancer 2009. V.45. P.2649-2658.

17. Arbyn M, Martin-Hirsch P, Buntinx F, et al. Triage of women with equivocal or low-grade cervical cytology results: a metaanalysis of the HPV test positivity rate.//J Cell Mol Med. 2009. V.13. P.648-659.

18. Crusswell J. M.. Rancoholf D. F., Rramer B. S. Principles of cancer screening: Lessons from history and study design issues.//Semin Oncol. 2010. V.37. P.202-215.

19. European Commission. European Guidelines for Quality Assurance in Cervical Cancer Screening (Second Edition). Arbyn M, Anttila A, Jordan J, Ronco G, Schenck U, Segnan N, Wiener HG, Herbert A, Daniel J, von Karsa L (eds). Office for Official Publications of the European Communities, Luxembourg (2008).

20. Sasieni P., Adams J., Cuzick J. Benefit of at different ages: evidence from the UK audit of screening histories.//Br J Cancer. 2003. V.89. P.88-93.

21. Sasieni P., Castanon A., Cuzick J. Effectineness of cervical screening with age ${ }^{\wedge}$ population based case-control study of prospectively recorded data.//BMJ. 2009. V.339 P. b2968.

22. Shipitsyna E., Zolotoverkhaya E., Kuevda D et al. Prevalence of high-risk human papillomavirus types and cervical squamous intraepithelial lesion in women over 30 years of age in St. Peterburg, Russia.//Cancer Epidimiol. 2011. V.35. P.160-164.

23. The Bethesda System for reporting cervical cytology. Definition, criteria, and explanatory notes.D. Solomon, R. Nayar (eds).//Springer. 2004. XXIII. $191 \mathrm{p}$.

24. World Health Organization (WHO). Comprehensive Cervical Cancer Control. A guide to essential practice. Geneva: WHO 2006. 364 p. 
References: Russian.

1. Aksel' E.M. Statistika zlokachestvennyh novoobrazovanij zhenskoj polovoj sfery. // Onkoginekologija 2012. №1. S. 1823. Russian

2. Kaprin A.D., Starinskij V.V., Petrova G.V. Zlokachestvennye novoobrazovanija v Rossii v 2013 godu (zabolevaemost' i smertnost'). M: FGBU «MNIOI im. P.A. Gercena» Minzdrava Rossii 2015; 250 s. Russian

3. Kaprin A.D., Starinskij V.V., Petrova G.V. Osnovnye pokazateli sostojanija onkologicheskoj pomoshhi naseleniju Rossijskoj Federacii v 2013 g. M: FGBU «MNIOI im. P.A. Gercena» Minzdrava Rossii. 2014. 235 s. Russian

4. Kolomiec L. A., Churuksaeva O. N., Urazova L. N., Chernyshova A. L., Molchanov S. V., Muntjan A. B., Zamkova O. V., Vidjaeva I. G. Vakcinacija protiv VPCh - pervichnaja profilaktika raka shejki matki. Tomsk: Izd-vo "Pechatnaja manufaktura», 2011. 116 s. Russian

5. Kompleksnaja bor'ba s rakom shejki matki: Kratkoe prakticheskoe rukovodstvo .VOZ, 2010. 290 s. Russian

6. Novik V... Skrining raka shejki matki. // Prakticheskaja onkologija. 2010: №2. S.66-73. Russian

7. Profilaktika raka shejki matki: Rukovodstvo dlja vrachej. / Pod. Red. G.T. Suhih i V.N. Prilepskoj. M.: MEDpress-inform. 2012. 192 s. Russian

8. Rusakevich P. S. Virusnye izmenenija shejki matki, associirovannye s dobrokachestvennymi i predrakovymi porazhenijami: novye vozmozhnosti lechenija i profilaktiki / Rusakevich P. S., Shmak K. I., Grishanovich R. V. // Medicinskie novosti. 2010. № 3. S.79-84. Russian

9. Starinskij V.V., Petrova G.V., Grecova O.P. Jepidemiologija zlokachestvennyh novoobrazovanij /V kn. «Rukovodstvo po onkologii» /Pod red. V.I. Chissova, S.L. Dar'jalovoj. M.: OOO «Medicinskoe informacionnoe agentstvo». 2008. S. 30-44. Russian

10. Stern L. Piter, Kitchener S. Genri. (Red.) Vakciny dlja profilaktiki raka shejki matki. Pod redakciej Pitera L. Sterna, Genri S. Kitchenera. Moskva, 2011. 192 s. Russian

11. Uzhegova Zh.A., Grigorjan O.R., Grigorjan E.N. Sovremennye vozmozhnosti diagnostiki i lechenija predrakovyh zabolevanij shejki matki. // Rossijskij vestnik akushera-ginekologa. 2007. №1. P.28-34. Russian

12. Urmancheeva A.F. Rak shejki matki: skrining, diagnostika i stadirovanie. Obrazovatel'nyj kurs Evropejskogo obshhestva po medicinskoj onkologii // Onkoginekologija. 2006. P.275-28989. Russian

Информация об авторах::

1. Каприн Андрей Дмитриевич - д.м.н., профессор, член-корреспондент РАН, член-корреспондент РАО, Генеральный директор ФГБУ «НМИРЦ» Минздрава России

2. Новикова Елена Григорьевна - д.м.Н., профессор, МНИОИ им. П.А. Герцена - филиал ФГБУ “НМИРЦ» Минздрава России, руководитель гинекологического отделения отдела опухолей репродуктивных и мочевыводящих органов

3. Грецова Ольга Петровна - к.м.н. МНИОИ им. П.А. Герцена - филиал ФГБУ «НМИРЦ» Минздрава России, в.н.с. Российского центра информационных технологий и эпидемиологических исследований в области онкологии
13. Chissov V.I., Starinskij V.V., Mamontov A.S. Algoritmy vedenija onkologicheskih zabolevanij u naselenija Rossijskoj Federacii: Metodicheskie rekomendacii. M: FGBU «MNIOI im. P.A. Gercena» Minzdrava Rossii . 2010. Russian

14. Shabalova I.P. , Kasojan K.T. Citologicheskaja diagnostika zabolevanij shejki i tela matki. Triada Tver'. 2010. 382 s. Russian

15. American College of Obstetricians and Gynecologiests. ACOG Practice Bulletin number 109, December 2009: Cervical cytology screening. // Obstet Gynecol. 2009. V.114 P.1409-1420.

16. Anttila A, von Karsa L, Aasmaa A, et al. Cervical cancer screening policies and coverage in Europe. // Eur J Cancer 2009. V.45. P.2649-2658.

17. Arbyn M, Martin-Hirsch P, Buntinx F, et al. Triage of women with equivocal or low-grade cervical cytology results: a meta-analysis of the HPV test positivity rate. // J Cell Mol Med. 2009. V.13. P.648-659.

18. Crusswell J.M.. Rancoholf D.F., Rramer B.S. Principles of cancer screening: Lessons from history and study design issues. // Semin Oncol. 2010. V.37. P.202-215.

19. European Commission. European Guidelines for Quality Assurance in Cervical Cancer Screening (Second Edition). Arbyn $M$, Anttila A, Jordan J, Ronco G, Schenck U, Segnan N, Wiener HG, Herbert A, Daniel J, von Karsa L (eds). Office for Official Publications of the European Communities, Luxembourg (2008).

20. Sasieni P., Adams J., Cuzick J. Benefit of at different ages: evidence from the UK audit of screening histories. // Br J Cancer. 2003. V.89. P.88-93.

21. Sasieni P., Castanon A., Cuzick J. Effectineness of cervical screening with age $^{\wedge}$ population based case-control study of prospectively recorded data. // BMJ. 2009. V.339 P. b2968.

22. Shipitsyna E., Zolotoverkhaya E., Kuevda D et al. Prevalence of high-risk human papillomavirus types and cervical squamous intraepithelial lesion in women over 30 years of age in St. Peterburg, Russia.// Cancer Epidimiol. 2011. V.35. P.160-164.

23. The Bethesda System for reporting cervical cytology. Definition, criteria, and explanatory notes. D. Solomon, R. Nayar (eds). // Springer. 2004. XXIII. 191 p.

24. World Health Organization (WHO). Comprehensive Cervical Cancer Control. A guide to essential practice. Geneva: WHO 2006. 364 p.

Information about co-authors:

1. Kaprin A.D. - MD., professor, corresponding member of the Russian Academy of Sciences; corresponding member of the Russian Academy of education, Honored doctor of the Russian Federation, General Director NMRRC

2. Novikova E.G. - MD, professor, P. Hertsen MORI, head of the gynecological Department of the division of tumors of the reproductive and urinary organs

3. Gretzova O. P. - PhD, P. Hertsen MORI, leading researcher of Russian Center of informational technologies and epidemiological researching in oncology 